\title{
Occupational lead exposure among automotive garage workers - a case study for Jimma town, Ethiopia
}

\author{
Yalemsew Adela', Argaw Ambelu ${ }^{1}$ and Dejene A Tessema ${ }^{2 *}$
}

\begin{abstract}
Background: In Ethiopia, although there are numerous small-scale and medium industries which use lead-based raw materials that may pose health risks to workers, there are no workplace regulations for lead exposure. Moreover, there are no studies carried out on the blood lead levels (BLLS) of workers or on the contribution of common workplace practices to lead poisoning.

Method: A cross-sectional study on the BLLs of 45 automotive garage workers and 40 non-garage workers was carried out in the town of Jimma, Ethiopia. In addition to BLL analysis, data on some risk factors such as smoking, and chewing 'khat' (the leaves of Catha adulis) were gathered through structured questionnaires and interviews and data analysis was performed using SPSS (version 16). The t-test was used to compare mean BLLs of study groups. The analysis of variance (ANOVA), Kruskal-Wallis, Pearson chi-square and odds ratio tests were used to investigate the associations between specific job type, smoking and/or 'khat' chewing, service years and occurrence of non-specific symptoms with BLLS.
\end{abstract}

Results: The mean BLL of the automotive-garage workers was found to be significantly greater than that of the controls. The BLLs of all the lead-exposed individuals were found to be over $10 \mu \mathrm{g} / \mathrm{dL}$, and $53 \%$ of them had BLLs ranging $12-20 \mu \mathrm{g} / \mathrm{dL}$, with the remaining $47 \%$ having over $20 \mu \mathrm{g} / \mathrm{dL}$. The BLL of the workers increased with the duration of working in an automotive garage. Individuals involved in manual car painting comprise a larger percentage (58\%) of those with the highest BLLS ( $\geq 20 \mu \mathrm{g} / \mathrm{dL}$ ). Lead accumulation in individuals who chew 'khat' in the work place was found to be faster than in those who are not used to chewing 'khat'. 'Khat' is an evergreen shrub native to tropical East Africa, with dark green opposite leaves which are chewed when fresh for their stimulating effects.

Conclusion: The findings of the study have clearly demonstrated that the BLLs of automotive-garage workers in Jimma town are considerably high with a range of $11.73-36.52 \mu \mathrm{g} / \mathrm{dL}$ and the workers are in danger of impending lead toxicity. The BLLS of the workers are influenced by their occupational practices, chewing Catha adulis leaves at the workplace, and the time spent working in an automotive garage.

Keywords: Lead, Garage workers, Blood lead level, 'khat' (Catha adulis), Ethiopia

\footnotetext{
* Correspondence: dayeletese@gmail.com

${ }^{2}$ Department of Chemistry, College of Natural Sciences, Jimma University, Jimma, Ethiopia

Full list of author information is available at the end of the article
} 


\section{Background}

Lead is one of the most widely distributed toxins in our environment. Although its toxic effects have been known for centuries, occupational exposure to lead that results in poisoning, be it moderately or clinically symptomatic, is still common in many countries of the world $[1,2]$. Excessive occupational exposure over a brief period of time can cause a syndrome of acute lead poisoning. Clinical findings in this syndrome include abdominal colic, constipation, fatigue and central nervous system dysfunction. With even greater doses, acute encephalopathy with coma and convulsions may occur, whereas in cases of milder exposures, headaches and personality changes may be the only signs of neurologic toxicity [3]. Children are particularly susceptible to lead intoxication that causes various neurological and behavioural problems, ranging from raised hearing threshold to reduction in intelligence quotient (IQ) at low blood lead concentrations. Although no threshold has been determined for the harmful effects of lead in children, a 1991 Centers for Disease Control and Prevention (CDC) Report has put the BLL of concern in children at $10 \mu \mathrm{g} /$ $\mathrm{dL}$. The level of concern has changed over the past few decades, from $60 \mu \mathrm{g} / \mathrm{dL}$ (1960), to $30 \mu \mathrm{g} / \mathrm{dL}$ (1970), to $25 \mu \mathrm{g} / \mathrm{dL}$ (1985), to $10 \mu \mathrm{g} / \mathrm{dL}$ (1991) [4].

Occupational lead exposure in many developing countries is entirely unregulated, often with no monitoring of exposure [5]. In Ethiopia, although there are numerous small-scale and large industries which use lead-based raw materials that may pose health risks to workers, there are no workplace regulations for lead exposure and no data are available with the labour departments among the workers of small-scale lead-based units with regard to lead poisoning. Many people working for different manufacturing or service rendering organizations such as battery manufacturing workers, gas-station attendants, radiator repair workers, solderers of lead products, and welders, are involved in jobs which expose them to gradual health risks from exposure to lead without having any idea about the materials they are handling. Due to lack of awareness about their exposure, workers usually eat, smoke or drink while at work and such workplace practices may aggravate their exposure [6,7].

In Ethiopia and in some other East African countries, 'khat' chewing at the workplace is a common practice. 'Khat' (Catha adulis) is an evergreen shrub native to tropical East Africa, with dark green opposite leaves. The leaves of 'khat' are chewed fresh for their stimulating effects. After chewing the leaves, people may swallow the juice and throw away the residue or swallow whatever they chewed. In many work areas, the workers who chew 'khat' do so at the workplace. This is typically done by cutting the leaves and putting them into the mouth from time to time while performing duties. Whatever the material is that the workers are handling, they do not wash their hands each time they cut and put the leaves into their mouth. As a result, the various toxic substances, including lead, that have stuck to the hands of these workers might easily get transferred onto the 'khat' leaf surface and then ingested with the 'khat' by the workers.

Relating the concentration of heavy metals, such as lead, in humans to an environmental and occupational level is crucial in order to determine areas of health risk. Most toxicology studies rely on blood lead level as the measure of exposure [8-10]. Lead in shed deciduous teeth is sometimes quoted being regarded as a record of past lead exposure [11,12]. Other materials that have been used to estimate the amount of lead in human beings include hair [13-15], urine and faeces [16,17].

Auto-garage workers in Ethiopia are involved in car painting, soldering, welding and other repairing activities. The garage compounds in which the workers carry out their daily activities are usually filled with fuel exhaust from automobiles entering or leaving the garage's compounds. Moreover, workplace 'khat' chewing is common practice for many auto-garage workers. Most of the workers have no idea about the toxic metals they might be exposed to; as a result, they pay little attention to protecting themselves from the possible inhalation or ingestion of such toxic substances, nor are they given awareness on the issue or advised to take the necessary protective measures. Despite this fact, no study has been conducted to assess the BLLs of people working in autogarages or of workers in other industries that are expected to pose health risks to workers. However, a single cross-sectional study on the occupational lead exposure of 51 workers in lead acid battery repair units of transport service enterprises at Addis Ababa, using $\delta$ Aminolevulinic acid ( $\delta$-ALA) levels in the urine and serum as a biomarker, has been reported [18].

Jimma is one of the largest towns in Southwestern Ethiopia, located in the Jimma Zone of the Oromia Region (Figure 1). Based on figures from the Central Statistical Agency in 2005, this town has an estimated total population of 159,009 of whom 80,897 were men and 78,112 women [19].

According to data obtained from the zone's Trade and Industry office, there are a total of about 33 small-scale industries involved in furniture production, food processing, metal and woodwork, bakery and pastry, flourmaking, and coffee processing. There are no large-scale industrial activities in the town which are expected to expose workers to lead pollution. It could also be assumed in Jimma that, despite the continued use of leaded gasoline, a situation where lead emissions from motor vehicles would constitute a serious risk to public health is not anticipated, due principally to the relatively 


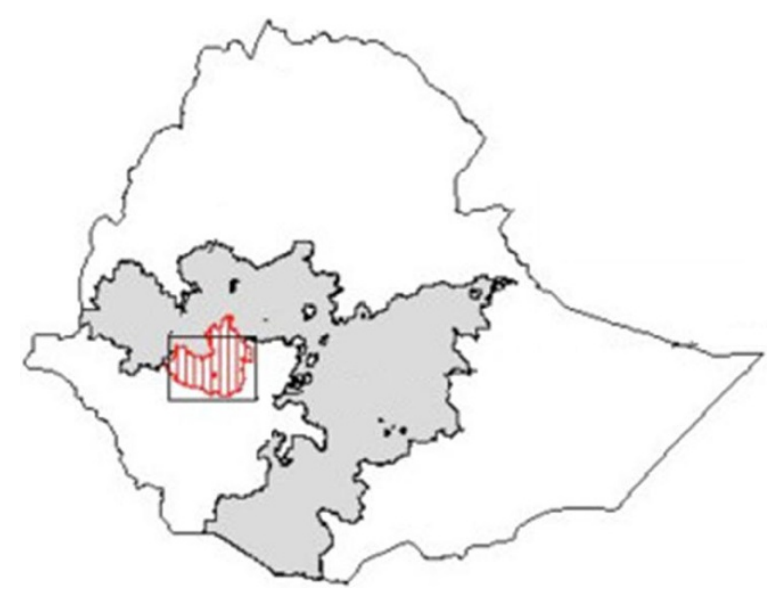

Figure 1 Location of Oromia Regional State (solid shading) and Jimma zone (vertical shading) within Ethiopia.

small number of cars in relation to the size of the town. Such a conclusion, however, would not be valid without evidence of completed work.

There are about 23 automotive garages in the town, each of which has an average of 15 workers. All of these garages offer multiple auto-repair services in a single compound. Within this compound, all workers carry out their specific jobs near other colleagues engaged in other activities, moving around to share tools and help one another. Therefore, all the workers are exposed virtually to the same extent to the toxic substances resulting from all the services offered in the auto-garage. The problem of exposure may be further compounded with the chewing of 'khat' at the work place. Preliminary observations have revealed that the automotive-garage workers who are used to chewing 'khat' while at work are taking the 'khat' under poor hygienic conditions and all of them have no idea about the possible toxic substances they might ingest with the 'khat' or inhale from the surrounding air. As a result, they use no protective devices to minimize exposure. Therefore, the BLLs of automotive garage workers around Jimma might be higher than other people who are not occupationally exposed. On top of this, auto garage workers who are used to workplace 'khat' chewing and smoking might have higher BLLs than their colleagues who are not used to practicing these habits while at work. This study was therefore aimed at investigating the BLLs and associated health problems of automotive garage workers in Jimma and relating the data to workplace practices of chewing 'khat' and smoking.

\section{Methods}

\section{Study subjects and study design}

The study was a cross-sectional BLL survey that included blood lead sampling from 45 occupationally exposed garage workers (44 males, 1 female) and 40 controls (36 males, 4 females). The occupationally exposed group included individuals who were mainly involved in manual auto spray-painting or welding for a duration of between 1 to 25 years in the autogarages where excessive usage of petrol and petroleum by-products takes place with a daily exposure of 8 to 12 hours. The occupationally non-exposed group members were university students and teachers who had apparently no history of lead exposure, were nonsmokers, non-khat chewers and non-alcoholics.

\section{Reagents and laboratory ware}

Analytical standard solutions of lead were prepared by serially diluting a $1000 \mathrm{mg} / \mathrm{L}$ stock calibration standard solution (Spectro ECON). All chemicals and reagents used were of analytical grade purchased from Merck (Darmstadt) or Sigma Chemical Co.

\section{Blood sample collection}

Venous blood samples $(4 \mathrm{~mL}$ each) were collected from the 45 garage workers and, 40 apparently healthy nongarage workers using carefully labelled vacutainer tubes containing $7.2 \mathrm{mg} \mathrm{K}_{2}$ EDTA by qualified medical laboratory professionals. All samples were then preserved at $4^{\circ} \mathrm{C}$ until digestion.

Blood specimen collection was carried out using separate sterilized needles and gloves for each individual. All used needles and gloves were packed in appropriately labelled disposable bags and taken to the Jimma University Specialized Hospital waste disposal unit.

\section{Sample preparation}

The blood specimens were heated in a hot water bath at $37^{\circ} \mathrm{C}$ for twenty five minutes and homogenized by shaking for one minute. Accurately measured three $\mathrm{mL}$ of each of the blood samples was transferred into a Pyrex test tube. A 3:1 mixture of trichloroacetic acid (TCA 5\%) and perchloric acid solution (2 M) was added into each test tube and centrifuged for 25 minutes at 3000 r.p.m. The supernatant from each sample was decanted into a labelled sample bottle and the precipitate was further digested with $3.0 \mathrm{~mL} 2 \mathrm{M}$ perchloric acid and centrifuged for 15 minutes. The supernatant from each centrifuged sample was decanted and mixed with its corresponding supernatant from the first digestion. Finally, the digests were stored at $-4^{\circ} \mathrm{C}$ until dispatched for analysis.

\section{BLL analysis}

The concentration of lead in the blood samples was determined by Flame Atomic Absorption Spectrometer (NovAA 300) at $283.3 \mathrm{~nm}$ after optimizing the various instrument parameters. Triplicate samples were analyzed 
in each determination and averages of triplicate measurements were taken for each sample. Instrument drift was controlled by running standards after analyzing 10 samples. Quantification of lead in blood was carried out with the help of a standard lead solution. Percentage recoveries determined from blood samples fortified with $10 \mu \mathrm{g}$ of lead per $4.0 \mathrm{~mL}$ of blood sample averaged 94.6\%. However, no correction for recoveries was performed in our data.

\section{Data collection}

In addition to determining the concentration of lead in blood samples, data on some risk factors for lead poisoning such as: addiction to alcohol, smoking, 'khat' chewing, and eating and/or drinking habits at the workplace, were gathered through questionnaires and interviews. A standardized structured questionnaire, designed to yield information on associated risk factors with the observed BLL, was prepared in English and administered after obtaining consent from the participants of the study. Each item in the questionnaire was interpreted into the local language for those who do not understand English. In addition to the questionnaire, participants were interviewed privately on further points. The interviews included detailed demographic information, exposure history and the presence and nature of lead-related symptoms.

\section{Statistical analysis}

Statistical analyses of results were basically performed by using SPSS (version 16). Comparison of mean BLLs of study groups was carried out using a $t$-test. One-way ANOVA was used to investigate the variation in BLL with the specific job types of the auto-garage workers. The Pearson chi-square statistic and the odds ratio test were used to investigate the associations between BLL and service years, and BLL and occurrence of nonspecific symptoms, respectively. The Kruskal-Wallis test was used to investigate the dependence of BLL on smoking and/or 'khat' chewing habit in the workplace. All data were expressed as mean $\pm \mathrm{SD}$ and the level of significance was determined at $\mathrm{p}<0.05$.

\section{Ethical consideration}

The study was conducted upon obtaining ethical approval by the Jimma University Ethical and Research Committee. The purpose of the study was clearly explained to the study participants following a pre-developed procedure and oral consent was obtained from each of the participating individuals and the auto-garage owners.

Blood specimen collection was carried out using a separate sterilized needle and glove for every individual. All used needles and gloves were packed in appropriately labelled disposable bags and taken to the Jimma University Specialized Hospital waste disposal unit.

\section{Results and discussion \\ BLLs of occupationally exposed and non-exposed groups}

The mean lead concentrations of the garage workers and controls are given in Table 1 . According to the $t$-test the difference between the mean BLL of the garage workers, $19.76 \mu \mathrm{g} / \mathrm{dL}$ (95\% CI: 18.45 - 21.06, median: $19.75 \mu \mathrm{g} / \mathrm{dL}$; range: $11.73-36.52 \mu \mathrm{g} / \mathrm{dL})$, and that of the controls, $10.73 \mu \mathrm{g} / \mathrm{dL}$ (95\% CI: 10.05 - 11.41, median: $10.40 \mu \mathrm{g} / \mathrm{dL}$; range: $5.6-15.64 \mu \mathrm{g} / \mathrm{dL})$ is significant $(\mathrm{p}<0.05)$.

The BLLs of the auto garage workers were found to vary with the specific job type they are involved in. The mean BLL of the workers involved in manual auto painting was $21.12 \pm 5.59 \mu \mathrm{g} / \mathrm{dL}$, that of welders $19.19 \pm 4.08 \mu \mathrm{g} / \mathrm{dL}$, and that of workers involved in both job categories $20.30 \pm 4.52$. The observed differences, however, were not statistically significant $(p>0.05)$. The BLLs of the garage workers were all greater than $10 \mu \mathrm{g} / \mathrm{dL}$, while $41 \%$ of the controls had BLLs lower than this value. The remaining $59 \%$ of the controls had BLLs ranging $10-16 \mu \mathrm{g} / \mathrm{dL}$. Among the garage workers, 53\% had BLLs ranging from 12 to $20 \mu \mathrm{g} / \mathrm{dL}$, and the remaining $44 \%$ of them had 20 to $27 \mu \mathrm{g} / \mathrm{dL}$. One person among the garage workers had a relatively higher $\mathrm{BLL}, 36.52 \mu \mathrm{g} / \mathrm{dL}$, and the person was identified to be an alcoholic, smoker, 'khat' chewer, and had served for 25 years in auto garages. The female garage worker who participated in the study had a BLL of $15.87 \mu \mathrm{g} / \mathrm{dL}$. She had served for over 10 years, and did not chew 'khat', smoke or drink alcohol. The mean BLL of the four females among the controls was $10.13 \mu \mathrm{g} / \mathrm{dL}$ (95\% CI: 9.36 - 10.90, median: $9.96 \mu \mathrm{g} / \mathrm{dL}$; range: 9.38 $11.22 \mu \mathrm{g} / \mathrm{dL})$.

\section{BLLs of occupationally exposed group relative to service years}

The proportion of individuals with BLLs less than 15, 15 to 20 or above $20 \mu \mathrm{g} / \mathrm{dL}$ among the garage workers with service years between 1-3, $3-6$ and above 6 years are given in Figure 2. The figure clearly shows a steady increase in the proportion of individuals with higher BLLs

Table 1 BLLs of the garage workers and controls

\begin{tabular}{lccc}
\hline Category & Mean Pb conc $(\boldsymbol{\mu g} / \mathbf{d L} \pm \mathbf{S D})$ & $\mathbf{9 5 \%} \mathbf{C l}(\boldsymbol{\mu g} / \mathbf{d L})$ & $\mathbf{R a n g e}(\boldsymbol{\mu g} / \mathbf{d L})$ \\
\hline Garage workers & $19.75 \pm 4.46$ & $18.45-21.06$ & $11.73-36.52$ \\
Controls & $10.73 \pm 2.22$ & $10.05-11 . .41$ & $5.6-15.64$ \\
\hline
\end{tabular}




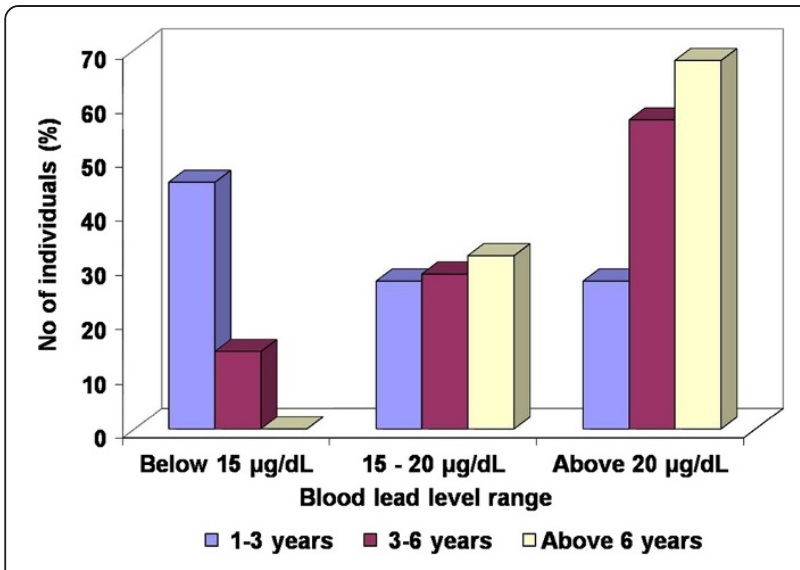

Figure 2 Proportion of the garage workers with BLLs less than $15 \mu \mathrm{g} / \mathrm{dL}$, between 15 to $20 \mu \mathrm{g} / \mathrm{dL}$ and above $20 \mu \mathrm{g} / \mathrm{dL}$ in the $1-3,3-6$ and above 6 years of service categories.

with an increase in service years. The chi-square test has revealed that the dependence of BLL on service years is statistically significant $(p<0.05)$. Among the individuals in the $1-3$ service year group, the relative number of individuals with BLLs of less than $15 \mu \mathrm{g} / \mathrm{dL}$ is greater than that of individuals with BLLs ranging from 15 to $20 \mu \mathrm{g} / \mathrm{dL}$ or above $20 \mu \mathrm{g} / \mathrm{dL}$. Forty-six percent of the garage workers with service between $1-3$ years and $14 \%$ of those with service between $3-6$ years were found to have BLLs less than $15 \mu \mathrm{g} / \mathrm{dL}$.

Among the workers with more than 6 years of service, $68 \%$ had BLLs above $20 \mu \mathrm{g} / \mathrm{dL}, 32 \%$ in the range from 15 to $20 \mu \mathrm{g} / \mathrm{dL}$ and none of them had less than $15 \mu \mathrm{g} /$ dL. Individuals with more than 10 years of service comprise a larger percentage (88\%) of those with BLLs above $20 \mu \mathrm{g} / \mathrm{dL}$. This clearly shows the direct relationship between BLL and service years.

\section{BLL and smoking/'khat'-chewing habits}

The mean BLL of the total garage workers who were neither smokers nor 'Khat' chewers was $16.58 \pm 3.5 \mu \mathrm{g} / \mathrm{dL}$ $(\mathrm{n}=14)$ and that of the 'Khat'- chewing non smokers was $20.17 \pm 3.11 \mu \mathrm{g} / \mathrm{dL} \quad(\mathrm{n}=25)$. According to the KruskalWallis test, the observed BLL difference between the two groups is significant $(p<0.05)$. Table 2 illustrates the mean BLLs of the garage workers who were 'khat' chewers but not smokers and, non-khat chewers and non-smokers in the service year ranges of 1 to 3,3 to 6 and above 6 years. As shown in this table, among the 11 individuals with service years ranging 1 to 3 years, the mean BLL of those who were habituated neither to 'khat' chewing nor to smoking had a mean BLL of $12.57 \pm 0.88 \mu \mathrm{g} / \mathrm{dL}(\mathrm{n}=4)$. However, those who were non-smokers but habituated to 'khat' chewing had a mean BLL of $20.19 \pm 4.06 \mu \mathrm{g} / \mathrm{dL}$ $(\mathrm{n}=7)$. Six of the seven 'khat' chewers had BLLs above $18 \mu \mathrm{g} / \mathrm{dL}$ and only one individual had a BLL of $13.89 \mu \mathrm{g} /$ $\mathrm{dL}$. The fact that both the 'khat' chewers and nonchewers are not smokers and that the BLLs of the nonkhat chewers is significantly lower than that of the 'khat' chewers indicates that 'khat' chewing either accelerates lead accumulation or is an additional source of lead intake. A similar difference between the two groups was not observed in the BLLs of the individuals with more than 3 years of service in the auto garages. The impact of 'khat' chewing on lead accumulation steadily decreased with service years, and in individuals with more than 10 years of service its impact was not visible.

\section{Lead toxicity symptoms}

The odds ratio of the reported non-specific symptoms in the garage workers in relation to the controls was calculated and the results obtained are shown in Table 3. The results clearly show that among the reported non-specific

Table 2 Relationship of BLL with smoking, 'khat' chewing, and/or smoking habit and service years

\begin{tabular}{|c|c|c|c|c|c|c|c|}
\hline Service Years & 'Khat' Chewing & Smoking & $\mathbf{n}$ & Mean BLL $(\mu \mathrm{g} / \mathrm{dL})$ & Range $(\mu \mathrm{g} / \mathrm{dL})$ & Median $(\mu \mathrm{g} / \mathrm{dL})$ & $\mathrm{Cl}(p=0.05)(\mu \mathrm{g} / \mathrm{dL})$ \\
\hline \multirow[t]{4}{*}{$1-3$ years } & $x$ & $x$ & 4 & 12.57 & $11.73-13.8$ & 12.37 & $11.69-13.45$ \\
\hline & $\sqrt{ }$ & $\sqrt{ }$ & - & - & - & - & \\
\hline & $\sqrt{ }$ & $x$ & 7 & 20.19 & $13.89-27.1$ & 19.91 & $16.13-24.25$ \\
\hline & $x$ & $\sqrt{ }$ & - & - & - & - & \\
\hline \multirow[t]{4}{*}{3 - 6years } & $x$ & $x$ & 2 & 18.51 & $16.51 \& 20.51^{*}$ & - & $14.59-22.43$ \\
\hline & $\sqrt{ }$ & $\sqrt{ }$ & 1 & 21.99 & - & - & - \\
\hline & $\sqrt{ }$ & $\times$ & 4 & 22.04 & $18.21-25.94$ & 22 & $18.87-23.21$ \\
\hline & $x$ & $\sqrt{ }$ & - & - & - & - & - \\
\hline \multirow[t]{4}{*}{ Above 6 years } & $x$ & $x$ & 8 & 18.94 & $15.87-21.68$ & 19.61 & $17.25-20.63$ \\
\hline & $\sqrt{ }$ & $\sqrt{ }$ & 3 & 25.46 & $19.58-36.52$ & 20.29 & $14.63-36.3$ \\
\hline & $\sqrt{ }$ & $\times$ & 14 & 19.63 & $15.66-23.69$ & 19.06 & $18.29-20.97$ \\
\hline & $x$ & $\sqrt{ }$ & 2 & 25.16 & $24.08 \& 26.23^{*}$ & - & $23.06-27.26$ \\
\hline
\end{tabular}

$\mathrm{n}=$ number of workers, $\mathrm{X}=$ Not smoking or 'Khat' chewing, $\sqrt{ }=$ Smoking or 'Khat' chewing.

${ }^{*}$ where $n=2$, both blood lead concentrations are given in place of the range. 
Table 3 Reported symptoms among the occupationally exposed $(n=45)$ and the controls $(n=40)$ and the ratio of their odds

\begin{tabular}{lcccc}
\hline \multicolumn{5}{c}{ № of 'Yes' response for symptom } \\
\hline Symptom & Cases & Controls & Odds Ratio & p-value \\
\hline Depression & 28 & 7 & $7.76^{*}$ & 0.00 \\
Memory impairment & 13 & 6 & 2.30 & 0.21 \\
Sleep disturbance & 23 & 9 & $3.60^{*}$ & 0.01 \\
Concentration difficulty & 9 & 11 & 0.66 & 0.32 \\
Headaches & 17 & 14 & 1.13 & 0.91 \\
Wrist drop & 25 & 1 & $48.75^{*}$ & 0.00 \\
Tingling \& numbness & 12 & 1 & $14.18^{*}$ & 0.01 \\
in fingers/hands & & & & \\
Lack of appetite & 12 & 5 & 2.55 & 0.18 \\
Nausea & 10 & 1 & $11.14^{*}$ & 0.02 \\
Constipation & 10 & 3 & 3.52 & 0.13 \\
Abdominal discomfort & 16 & 8 & 2.21 & 0.17 \\
Decreased libido & 21 & 3 & $10.79^{*}$ & 0.00 \\
\hline * significant retative risk of occurrence in the auto garage works at $\boldsymbol{p}<0.05$
\end{tabular}

* significant relative risk of occurrence in the auto garage workers at $p<0.05$.

symptoms, the occurrence of wrist drop, tingling and numbness in fingers and hands, nausea, and decreased libido in the auto garage workers are significantly greater than in the controls.

The proportion of individuals affected by the nonspecific symptoms among the individuals with BLLs: less than 16,16 to 20 or above $20 \mu \mathrm{g} / \mathrm{dL}$, was assessed and the results obtained are illustrated in Figure 3. The results clearly indicated an increase in the prevalence of all the symptoms with an increase in BLL.

Among the symptoms assessed, depression, wrist drop, and decreased libido were the most prevalent ones in

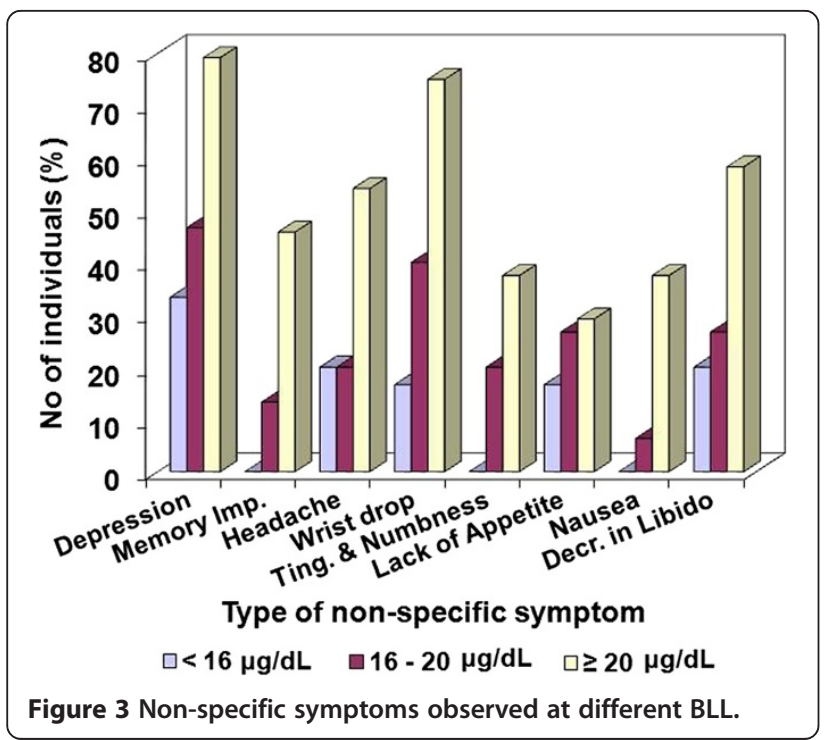

the individuals with BLLs $\geq 20 \mu \mathrm{g} / \mathrm{dL}$. About $80 \%$ of the garage workers in this BLL range reported having symptoms of depression, $75 \%$ for wrist drop and $58 \%$ for decreased libido.

Results of the odds ratio test for the relative occurrence of the non-specific symptoms between the garage workers with BLLs of less than $20 \mu \mathrm{g} / \mathrm{dL}(\mathrm{n}=25)$ and the controls $(n=40)$ are given in Table 4. The results clearly show that the occurrence of most of the symptoms in the garage workers is significantly greater than in the controls $(p<0.05)$. This could be a clear indication for the negative health impacts of BLLs as low as $10 \mu \mathrm{g} / \mathrm{dL}$.

During interviews, the garage workers reported some non-specific symptoms which were not included in the questionnaire. Among the workers, 15 (33.3\%) reported having developed a feeling of metallic taste in their mouth, 9 (20\%) reported having blurred vision, and 11 (24.4\%) had dry white scars in one or two areas on their heads.

\section{Discussion}

Occupationally related BLL assessment has not previously been carried out in any part of Ethiopia. However, in a cross-sectional study carried out in Addis Ababa on lead exposure among storage battery repair workers by measuring urinary aminolevulinic acid levels, higher levels of urinary aminolevulinic acid were found in the storage battery repair workers and the possible parallel rise in BLLs of the workers was predicted. The results obtained in our study have shown that auto-garage

Table 4 Reported symptoms among the auto garage workers with BLLs less than $20 \mu \mathrm{g} / \mathrm{dL}(\mathrm{n}=25)$ and the controls $(n=40)$ and the ratio of their odds

\begin{tabular}{lcccc}
\hline \multicolumn{5}{c}{ Yes responses for symptoms } \\
\hline Symptoms & Cases & Controls & Odds ratio & $\mathbf{p}$ \\
\hline Depression & 28 & 7 & $5.11^{*}$ & 0.02 \\
Memory impairment & 13 & 6 & 1.08 & 0.61 \\
Sleep disturbance & 23 & 9 & $3.18^{*}$ & 0.01 \\
Concentration difficulty & 9 & 11 & 0.50 & 0.55 \\
Headaches & 17 & 14 & 0.66 & 0.52 \\
Wrist drop & 25 & 1 & $26.00^{*}$ & 0.00 \\
Tingling \& numbness & 12 & 1 & $7.43^{*}$ & 0.04 \\
in fingers/hands & & & & \\
Lack of appetite & 12 & 5 & 2.20 & 0.06 \\
Nausea & 10 & 1 & $5.32^{*}$ & 0.04 \\
Constipation & 10 & 3 & 2.25 & 0.16 \\
Abdominal discomfort & 16 & 8 & 1.88 & 0.29 \\
Decreased libido & 21 & 3 & $8.22^{*}$ & 0.00 \\
\hline * significant relative risk of occurrence in the auto garage workers at $\mathrm{p}<0.05$.
\end{tabular}

* significant relative risk of occurrence in the auto garage workers at $p<0.05$. 
workers have significantly greater BLL than the non garage workers $(p<0.05)$. This clearly indicates that autogarage workers are more likely to be exposed to lead due to occupational incidences than the general population. Furthermore, the results obtained in our study are consistent with the results of other studies carried out on the determination of the BLLs of: ninety-seven occupationally and non-occupationally exposed individuals in $\mathrm{Ni}$ geria [20], workers involved in various types of jobs in the United Arab Emirates [21], thirty one male non-smoking industrial workers in Iran [22], and apprentices working in lead-related industries in Turkey [6]. Among the leadexposed garage workers, the mean BLL of individuals who were mainly involved in manual auto painting $(21.12 \pm 5.59 \mu \mathrm{g} / \mathrm{dL})$ was slightly higher than that of the mechanics $(19.19 \pm 4.08 \mu \mathrm{g} / \mathrm{dL})$. Comparison of the mean values by using a $t$-test has shown that the observed difference was not, however, statistically significant. A study done in Bangkok on 52 mechanics, 27 dye sprayer and 20 controls, reported mean BLLs of $8.7 \mu \mathrm{g} / \mathrm{dL}, 12.02 \mu \mathrm{g} / \mathrm{dL}$ and $6.63 \mu \mathrm{g} / \mathrm{dL}$, respectively [23]. The mean BLLs obtained by these researchers for all the three groups were much lower than those obtained in our study. The relative difference between the BLLs of the mechanics and the auto-painters in their study (27.6\%), however, is greater than that of the difference obtained in our study (9.1\%). The observed higher BLL in the painters than in the mechanics might indicate a greater exposure of the dye sprayers relative to the mechanics. The painters, in addition to the oral exposure routes, are more likely exposed to inhalation of lead fumes found in the dyes than those workers engaged in other auto-repairing activities. This could be a possible reason for the observed BLL difference between the two groups.

The garage workers were found to exhibit significantly higher levels of the non-specific symptoms which included: depression, sleep disturbance, wrist drop, tingling and numbness in fingers and hands, nausea, and decrease in libido relative to the controls. Moreover, the prevalence of these symptoms was higher in the workers with higher service years than in those with lower service years. Comparison of the prevalence of the non-specific symptoms between the occupationally exposed individuals with BLLs less than $20 \mu \mathrm{g} / \mathrm{dL}(\mathrm{n}=25)$ with that of the controls $(n=40)$ has also revealed that there is a significantly greater prevalence of most of the symptoms in the garage workers. The Association of Occupational and Environmental Clinics (AOEC) has revealed the health effects of various BLLs on lead-exposed adults, and according to this document, the non-specific symptoms such as: headache, sleep disturbance, fatigue, and decreased libido are shown to occur in the BLL range between 20 and $39 \mu \mathrm{g} / \mathrm{dL}$ [24]. However, the findings of our study suggest that these symptoms are exhibited by lead-exposed individuals at lower BLLs $(10-20 \mu \mathrm{g} / \mathrm{dL})$ than indicated in the AOEC document. Our report on the variations of the non-specific symptoms between the two groups is entirely from what the two groups revealed in the questionnaires and interviews. Although this may be suggestive of the adverse effects of lead $(\mathrm{Pb})$ on the exposed individuals relative to the nonexposed, a close medical investigation is required to affirm that the epidemiologic variations between the two groups are exclusively results of the difference in the BLLs of the groups.

'Khat' chewing has been found to enhance lead accumulation in the first $1-3$ years of service in the occupationally exposed individuals. The mean BLL of the 'khat' chewers in the $1-3$ service year range was $61 \%$ higher than the mean BLL of the non-chewers in the same service year range. The observed elevated level of lead in the 'khat' chewers could most likely be due to oral ingestion. The garage workers are chewing 'khat' at the workplace. Moreover, they chew the 'khat' while carrying out their work and do not wash their hands each time they cut the leaves and put them in their mouth. This makes lead entry into the digestive system easier, thereby increasing BLL.

Several potential limitations of our study may have affected the analysis. The records of environmental $\mathrm{Pb}$ exposure in the proximity of the auto-garages were not available because monitoring of $\mathrm{Pb}$ in air was not enforced. Any observed difference in response to occupational and environmental $\mathrm{Pb}$ exposure may, therefore, be attributed to a degree of exposure to $\mathrm{Pb}$. The participants in the control group were selected from university students and teachers. As a result, absence of some epidemiological symptoms in this group might not be exclusively attributed to lower BLL relative to the automotive-garage workers.

\section{Conclusion}

The BLLs of automotive-garage workers in Jimma town are noticeably high with a range of $11.73-36.52 \mu \mathrm{g} / \mathrm{dL}$ and the workers are in danger of impending lead toxicity. The BLLs of the workers are influenced by their occupational practices and roughly paralleled with the duration of occupational lead exposure. Workplace 'khat' chewing and lack of awareness about the ill health effects of lead and the routes through which it enters the human body has contributed to the easy entry of lead into the body of the workers and the resulting elevated BLL. Further large-scale screening and regular monitoring of auto-garage workers is urgently needed to reduce long term adverse effects of lead exposure.

\section{Competing interests}

The authors declare that they have no competing interests. 


\section{Authors' contributions}

YA carried out the sampling, analytical work and statistical analysis, AA participated in the design and coordination of the study and the statistical analysis. DAT conceived the study, participated in its design and coordination and prepared the manuscript. All authors read and approved the final manuscript.

\section{Author details}

${ }^{1}$ Department of Environmental Health Sciences, College of Public Health, Jimma University, Jimma, Ethiopia. ${ }^{2}$ Department of Chemistry, College of Natural Sciences, Jimma University, Jimma, Ethiopia.

Received: 19 February 2011 Accepted: 8 May 2012

Published: 9 July 2012

\section{References}

1. Vaglenov A, Creus A, Laltchev S, Petkova V, Pavlova S, Marcos R: Occupational exposure to lead and induction of genetic damage. Environ Health Perspect 2001, 109:295-298.

2. Bhagwat VR, Patil AJ, Patil JA, Sontakke AV: Occupational lead exposure and liver functions in battery manufacture workers around Kolhapur (Maharashtra). Al Ameen J Med Sci 2008, 1(1):2-9.

3. Landrigan PJ: Lead. In Textbook of clinical occupational and environmental medicine. Edited by Rosenstock L, Cullen MR. Philadelphia: Saunders; 1994:745-754.

4. Centers for Disease Control and Prevention: Preventing Lead Poisoning in Young Children: A Statement by the Centers for Disease Control. Atlanta: US Department of Health and Human Services, Public Health Service; 1991.

5. Lovei M: Eliminating a silent threat: World Bank support for the global phase-out of lead from gasoline. In Proceedings of the International Conference on Lead Poisoning Prevention and Treatment. Edited by George AM. Bangalore: The George Foundation; 1999:169-180.

6. Pala K, Turkkan A, Gucer S, Osman E, Aytekin H: Occupational lead exposure: blood lead levels of apprentices in Bursa, Turkey. Ind Health 2009, 47:97-102

7. Grandjean P, Hollnagel H, Olsen NB: Occupationally related lead exposure in the general population. Scand J Work Environ Health 1981, 7:298-301.

8. Baloh RW: Laboratory diagnosis of increased lead absorption. Arch Environ Health 1974, 28:198-208.

9. Landigran PJ, Whitworth RH, Baloh RW, Staehling NW, Bartle WF, Rosenblum BF: Neoropsychological dysfunction in children with chronic low-level lead absorption. Lancet 1975, 1708:12.

10. Ratcliffe JM: Developmental and behavioural function in young children with elevated blood lead levels. Br J Prev Med 1977, 31:258-264.

11. Needleman HL, Gunnoe C, Leviton A, Reed R, Persie H, Maher C, Barret: Deficits in psychologic and classroom performance of children with elevated dentine lead levels. N Engl J Med 1979, 300:689-695.

12. Cloag D: A cooler look at lead. Br Med J 1983, 286:1458-1459.

13. Phil RO, Parkes M: Hair element content in learning disabled children. Science 1977, 198:204-206.

14. Phil RO, Drake H, Vrana F: Hair analysis in learning and behaviour problems. In Hair, Trace Elements and Humanlllness. Edited by Brown AC, Crounse RG.: Praeger; 1980:128-143.

15. Thatcher RW, Loster ML, McAlaster R, Horst R: Effect of low levels of cadmium and lead on cognitive function of children. Arch Environ Health 1982, 37:159-166.

16. Chisholm JJ: Current status of lead exposure and poisoning of children. South Med J 1976, 69:529-531.

17. Hammond PB, Clark CS, Gartside PS, Berger O, Walker A, Michael LW: Faecal lead excretion in young children as related to sources of lead in their environment. Int Arch Occup Environ Health 1980, 46:191-202.

18. Ahmed K, Ayana G, Engidawork E: Lead exposure study among workers in lead acid battery repair units of transport service enterprises, Addis Ababa. Ethiopia: a cross-sectional study. Journal of Occupational Medicine and Toxicology 2005, 3:30.

19. Ethiopian Central Statistical Agency and ORC Macro: Ethiopia Demographic and Health Survey 2005. Maryland: Addis Ababa, Ethiopia and Calverton; 2005.

20. Fatoki OS, Ayoade D: Leady assay in blood of occupationally and nonoccupationally exposed. Int J Environ Health Res 1996, 6(3):195-200.
21. Berner A, Almehdi AM, Alwash R, Al-Neamy FRM: A pilot survey of blood lead levels in various types of workers in the United Arab Emirates. Environ Int 2001, 27:311-314.

22. Aliasgharpour $M$, Hagani $H$ : Impact of occupational lead exposure on industrial workers health condition in Tehran-Iran. Eastern Journal of Medicine 2005, 10:20-23.

23. Suwansaksri J, Teerasart N, Wiwanitkit V, Chaiyaset T: High blood lead leve among garage workers in Bangkok, public concern is necessary. Pubmed 2002, 15(4):367-370.

24. Medical Management Guidelines for Lead-Exposed Adults. www.aoec.org/ documents/positions/MMG_FINAL.pdf.

doi:10.1186/1745-6673-7-15

Cite this article as: Adela et al.: Occupational lead exposure among automotive garage workers - a case study for Jimma town, Ethiopia. Journal of Occupational Medicine and Toxicology 2012 7:15.

\section{Submit your next manuscript to BioMed Central and take full advantage of:}

- Convenient online submission

- Thorough peer review

- No space constraints or color figure charges

- Immediate publication on acceptance

- Inclusion in PubMed, CAS, Scopus and Google Scholar

- Research which is freely available for redistribution

Submit your manuscript at www.biomedcentral.com/submit
C Biomed Central 